\title{
Can reversibility of nasal obstruction predict the grade of bronchial hyperreactivity?
}

\author{
Perecinsky $\mathrm{S}^{1}$, Legath $\mathrm{L}^{1}$, Orolin $\mathrm{M}^{2}$ \\ Department of Occupational Medicine and Clinical Toxicology, Medical Faculty, PJ Safarik University, and the L Pasteur \\ University Hospital, Kosice, Slovakia. slavomir.perecinsky@upjs.sk
}

\begin{abstract}
Objective: Aim of the study was to reveal the connection between significance of nasal obstruction and bronchial hyperreactivity.

Background: Allergic rhinitis is the most common lgE-mediated disease with progressively increasing prevalence in population. Chronic inflammation and remodelation of mucosa of the upper airways can be a part of generalized affection of respiratory system including lower airways. Severe inflammatory damage of nasal mucosa is connected with irreversibility of nasal obstruction, which is possible to verify by nasal decongestion test. Methods: Bronchoprovocation test and rhinomanometry examination with decongestion test were performed in 57 patients. We analysed the grade of bronchial hyperreactivity and response of nasal mucosa to decongestion agent. Number of positive and negative decongestion tests were compared in a group of patients with mild bronchial hyperreactivity with the group of moderate and severe hyperreactivity.

Results: Comparing the results of decongestion tests there has been a significant difference found between the group with mild hyperreactivity and the group with moderate and severe hyperreactivity.

Conclusion: The study points out to narrow relationship between bronchial asthma and allergic rhinitis, where patients with negative decongestion test showed significantly increased grade of bronchial hyperreactivity. Due to this patients with insufficient response of nasal mucosa to decongestive agent probably require more intensive antiinflammatory therapy compared to patients with positive response. Nasal decongestion tests can be used for examination of the effect of allergic inflammation of nasal mucosa on the lower airways and vice versa (Tab. 4, Ref. 27). Full Text in PDF www.elis.sk.

Key words: nasal decongestion test, nasal obstruction, allergic rhinitis, bronchial hyperreactivity, rhinomanometry.
\end{abstract}

Allergic rhinitis is the most common IgE-mediated disease with increasing prevalency in population (1). It is characterized by several typical symptoms from which nasal obstruction is the most important and is associated with allergic inflammation (2). Nasal obstruction can be evaluated either subjectively by visual analogue scale, or objectively by measurement of nasal resistency by rhinomanometry. Measurement of nasal resistency offers quantitative evaluation of the significance of nasal obstruction (3).

Allergic rhinitis is significantly associated with irreversible nasal obstruction caused by chronic inflammation and remodelation of nasal mucosa (4). Chronic inflammation and remodelation of mucosa of the upper airways can be part of general dysruption of respiratory system including the lower airways. Eosinophilic inflammation is a characteristic sign of allergic diseases. Increased level of eosinophils in the blood is associated with allergic inflammation, however it is not specific (5). Increased level of IgE is typical for atopy.

${ }^{1}$ Department of Occupational Medicine and Clinical Toxicology, Medical Faculty, PJ Safarik University, and the L Pasteur University Hospital, Kosice, Slovakia, and ${ }^{2}$ Department of Respiratory Disorders and Tuberculosis, Medical Faculty, PJ Safarik University and the L Pasteur University Hospital, Kosice, Slovakia

Address for correspondence: S. Perecinsky, Dept of Occupational Medicine and Clinical Toxicology, Medical Faculty, PJ Safarik University, and the L Pasteur University Hospital, Trieda SNP 1, SK-041 90 Kosice, Slovakia. Phone: +421.55.6152680, Fax: +421.55.6152699
Several studies focuse on the important role of nasal provocation tests in the diagnostic algorithm of allergic rhinitis (6-11), however the importance of decongestion tests in clinical practice is not satisfactorily elucidated. There were several studies published which focused on nasal mucosa directly with nasal decongestion tests $(2,4,12-15)$, however studies that focuse on concomitant examination of reaction of the mucosa of upper and lower airways are very rare (1).

Nasal decongestion test evaluates percentual reversibility of nasal obstruction after intranasal application of vasoconstrictor agent (2). While bronchodilation test with beta-2-mimetics plays a key role in diagnosis of bronchial asthma, decongestion test is considered rather prognostic method for rhinitis (15).

The aim of our study was to evaluate the significance of nasal obstruction on the basis of response to decongestive agent in patients with mild bronchial hyperreactivity compared to patients with moderate and severe bronchial hyperreactivity. We observed also possible correlation of eosinophilia and increased serum concentration of total IgE antibodies with irreversible disruption of nasal mucosa and degree of bronchial hyperreactivity.

\section{Methods}

There were 68 patients with bronchial hyperreactivity and concomitant allergic rhinitis enrolled in to the study. 
Tab. 1. Average FlowT (ml/s) in patients' groups.

\begin{tabular}{|c|c|c|c|}
\hline Hyperreactivity & Basal & $\begin{array}{c}\text { After } \\
\text { decongestion }\end{array}$ & $\begin{array}{l}\text { Increase of } \\
\text { FlowT }(\%)\end{array}$ \\
\hline Mild & $601( \pm 138)$ & $873( \pm 169)$ & $+31 \%$ \\
\hline Moderate and severe & $585( \pm 163)$ & $686( \pm 175)$ & $+15 \%$ \\
\hline
\end{tabular}

Tab. 2. Results of decongestion tests (mild vs moderate and severe hyperreactivity).

\begin{tabular}{lccc}
\hline Decongestion test & positive & negative & $\begin{array}{c}\text { Chi-square } \\
\text { statistical } \\
\text { significance }\end{array}$ \\
\hline Mild hyperreactivity & 28 & 8 & $\mathrm{p}<0.001$ \\
Moderate and severe hyperreactivity & 6 & 15 & \\
\hline
\end{tabular}

Non specific bronchoconstriction test was performed for confirmation of the degree of bronchial hyperreactivity in all patients. For confirmation of concomitant rhinitis otorhinolaryngologist examination was performed. 11 patients with significant anatomical abnormalities in nasal cavity were excluded from the study. 57 patients underwent rhinomanometry examination with decongestion test. Serum IgE levels were detected in most patients, as well as serum eosinophil count.

\section{Bronchoprovocation test}

For confirmation of bronchial hyperreactivity aerosol of methacholin was used in 20 cases in double dose increased concentrations $(0.125,0.25,0.5,1.0,2.0,4.0,8.0,16.0 \mathrm{mg} / \mathrm{ml})$ with total cumulative dose of $230,9 \mu \mathrm{g}(16)$, in 48 cases aerosol of histamin was used in double dose increased concentrations $(0.1,0.2,0.4$, $0.8,1.5,3.0,6.0,12.0 \mathrm{mg} / \mathrm{ml}$ ) with total cumulative dose of 172,8 $\mu \mathrm{g}$ (17). Bronchoprovocation test was positive (i,e. bronchial hyperreactivity was confirmed) in case of $20 \%$ decrease of FEV1. On basis of $\mathrm{PC}_{20}$ the patients were divided in to the group with mild hyperreactiviyty and the group with moderate and severe bronchial hyperreactivity.

\section{Rhinomanometry}

Nasal flow was measured by anterior active rhinomanometry (Sanascope, Ganshorn Gmbh, Nemecko). Airflow through right nasal passage (Flow $\mathrm{R}(\mathrm{ml} / \mathrm{s})$ and left nasal passage (Flow $\mathrm{L}(\mathrm{ml} / \mathrm{s})$ ) and total airflow (Flow T $(\mathrm{ml} / \mathrm{s})$ ) with standardized pressure of 150 Pa was measured (basal rhinomanometry) (18).

\section{Decongestion test}

Immediately after basal rhinomanometry 2 doses of $0.2 \%$ xylomethasoline (Olynth) were applied to both nasal passages with subsequent application of 1 dose of xylomethasoline after 5 minutes. Rhinomanometry was repeated 15 minutes after basal rhinomanometry.

Decongestion test was positive in case of symmetrical increase of FlowT minimally for $120 \mathrm{ml} / \mathrm{s}$ (accordingly to minimally $25 \%$ increase of FlowT) (1). In case of non significant increase of FlowT or decrease of FlowT after decongestive agent, the test was evaluated as negative.

\section{Statistical analysis}

Statistical analysis was performed using Arcus QuickStat Biomedical and Microsoft Excel.Student t-test was used for comparison of FlowT values before and after decongestive agent administration. Comparison of positive and negative decongestive patients in the group with mild bronchial hyperreactivity compared to moderate and severe hyperreactivity was evaluated by Chi quadrate test and Fisher's test. Comparison of total serum IgE and eosinophils in the group of patients with mild bronchial hyperreactivity to the patients with moderate and severe hyperreactivity was performed using Fisher's test.

\section{Results}

In our group of 57 patients there were 25 men and 32 women with average age of $40( \pm 11.08)$ years from 20 to 61 years. 36 patients had mild hyperreactivity and 21 had moderate or severe bronchial hyperreactivity.

Average level of total airflow (FlowT) before administration of decongestive agent was $593 \mathrm{ml} / \mathrm{s}$, and after xylomethasoline it increased to $811 \mathrm{ml} / \mathrm{s}$. In Table 1 a summary and comparison of FlowT values in patients' groups is showed. In the group with mild hyperreactivity 28 tests were positive and 8 were negative, in the group with moderate and severe hyperreactivity there were 6 positive and 15 negative decongestion tests (Tab. 2). Comparing the results of decongestion tests there has been a significant difference found between the group with mild hyperreactivity and the group with moderate and severe hyperreactivity $(\mathrm{p}<0.001)$.

Results of total serum IgE antibodies and eosinophils are shown in tables 3 and 4 . Serum eosinophil count and total serum

Tab. 3. Total IgE antibodies (mild vs moderate and severe hyperreactivity).

\begin{tabular}{lcc}
\hline Concentrations of serum IgE & $\begin{array}{c}\text { Mild hyperreactivity number of } \\
\text { patients (in \%) }\end{array}$ & $\begin{array}{c}\text { Moderate and severe hyperreactivity } \\
\text { number of patients (in \%) }\end{array}$ \\
\hline Increased & $16(51.61 \%)$ & $12(85.71 \%)$ \\
Normal & $15(48.39 \%)$ & $2(14.29 \%)$ \\
\hline
\end{tabular}

Tab. 4. Serum eosinophil count (mild vs moderate and severe hyperreactivity).

\begin{tabular}{|c|c|c|c|}
\hline Serum eosinophil count & $\begin{array}{l}\text { Mild hyperreactivity number of } \\
\text { patients (in \%) }\end{array}$ & $\begin{array}{c}\text { Moderate and severe hyperreactivity } \\
\text { number of patients (in \%) }\end{array}$ & $\begin{array}{c}\text { Fisher's test statistical } \\
\text { significance }\end{array}$ \\
\hline Increased & $11(40.74 \%)$ & $10(76.92 \%)$ & \multirow{2}{*}{$\mathrm{p}<0.05$} \\
\hline Normal & $16(59.26 \%)$ & $3(23.08 \%)$ & \\
\hline
\end{tabular}


IgE was significantly higher in the group with moderate and severe hyperreactivity compared to the group with mild hyperreactivity $(\mathrm{p}<0.05)$.

\section{Discussion}

The aim of the study was to find a relationship between reversibility of nasal obstruction and significance of bronchial hyperreactivity verified by bronchoprovocation test.

Results of decongestion tests showed significantly positive effect of xylomethasoline in the group of patients with mild bronchial hyperreactivity on the increase of nasal flow in both nasal passages (FlowT) in average by $31 \%$, compared to non-significant decongestive effect in the patients with moderate and severe hyperreactivity with increase of nasal flow (FlowT) in average by $15 \%$. There was a statistically significant difference found between these two groups in positive and negative decongestion tests. In the group of patients with mild hyperreactivity there were 28 positive tests and 8 negative, whereas in the second group there were only 6 positive tests and 15 negative. The results pointed to negative correlation between reversibility of nasal obstruction and the grade of bronchial hyperreactivity. We suppose that nasal mucous membrane with inflammatory changes can lead to decreased xylomethasoline effect which was confirmed in Italian studies, where nasal mucosa with inflammatory changes showed weak response to decongestive agent (15).

On the contrary bronchial mucosa with inflammatory changes can lead to increased methacholine and histamine effect and increase of bronchial reactivity $(19,20)$.

It is shown, that grade of decreased reversibility of obstruction (verified by decongestion test) is associated with severity of allergic inflammation (verified by grade of hyperreactivity). It was shown in study of Ciprandi, in which he pointed to correlation of nasal flow and FEF25-75 and bronchial hyperreactivity, where decreased nasal airflow was a predisposition for bronchial disorder (21).

From this fact it is possible to conclude that decongestion tests can indirectly point to the grade of inflammation of nasal mucosa.

Our findings correlate with conclusions of other authors, where patients with positive decongestion test showed the lowest grade of bronchial hyperreactivity (1). This confirms close relationship between bronchial asthma and rhinitis (22-26).

Increased serum total IgE antibodies were higher in the group of patients with moderate and severe hyperreactivity compared to the group with mild hyperreactivity with statistically significant difference. There was an incresed serum eosinophil count found in the group with moderate and severe hyperreactivity compared to the group with mild hyperreactivity with statistically significant difference.

The importance of decongestion test comprises of confirmation of reversibility of nasal obstruction. The question is its usage as a method for distinguishing anatomical nasal abnormality (irreversible obstruction) from functional abnormality, which is caused by mucous edema (reversible obstruction) as was shown by some authors (27).

Nasal decongestion test is mainly a prognostic method which indirectly points to the significance of affection of nasal mucosa. It means that nasal mucosa with inflammatory changes showed weaker response to decongestive agent. Due to this fact the patients with insufficient response of nasal mucosa to decongestive agent probably need more intensive anti-inflammatory therapy compared to the patients with positive response.

Bronchial hypereactivity is a marker of disorder - inflammation of bronchial mucosa. Because of existency of connection between rhinitis and asthma, nasal decongestion tests can be used in further research on the influence of the allergic inflammation of nasal mucosa on the lower airways and vice versa, which was confirmed also by our results.

\section{References}

1. Ciprandi G, Cirillo I, Klersy C, Vizzaccaro A, Tosca MA, Marseglia GL. Nasal airflow recovery after decongestion test is associated with bronchial hyperreactivity in patients with allergic rhinitis. Otolaryng Head Neck 2006; 134: 255-259.

2. Ciprandi G, Cirillo I, Klersy C, Castellazzi AM, Barberberi S, Marseglia GL. Nasal decongestion test in allergic rhinitis: Definition of responder. Int Immunopharmacol 2007; 7: 372-374.

3. Cole P. Nasal airflow resistance: A survey of 2500 assessments. Am J Rhinol 1997; 11: 415-420.

4. Chawes BLK, Kreiner-Moller E, Bisgaard H. Objective assessment of allergic and nonallergic rhinitis in young children. Allergy 2009; 64: $1547-1553$.

5. Hrubisko M, Paulovicova E. Diagnostika alergie. 76-110. In: Hrubisko M (Ed). Alergológia. Martin: Vydavatelstvo Osveta, 2003.

6. Hytonen M, Sala E. Nasal provocation test in the diagnostics of occupational allergic rhinitis. Rhinology 1996; 34: 86-90.

7. Airaksinen LK, Tuomi TO, Tuppurainen MO, Lauerma AI, Toskala EM. Inhalation challenge in the diagnosis of occupational rhinitis. Am J Rhinol 2008; 22: 38-46.

8. Kujala V, Pirilä T, Niinimäki A, Reijula K. Latex-induced allergic rhitis in a laboratory nurse. J Laryngol Otol 1995; 109: 1094-1096.

9. Palczynski C, Walusiak J, Ruta U, Gorski P. Nasal provocation test in the diagnosis of natural rubber latex allergy. Allergy 2000; 55: 34-41.

10. Fernandes FR, Solé D, Naspitz Ch, Munoz-López F. Diagnostic value of nasal provocation testing and rhinomanometry in allergic rhinitis. J Invest Allerg Clin 1996; 6 (3): 184-188.

11. Wojdas A, Rapiejko P, Zielnik-Jurkiewicz B, Kantor I. Nasal provocative test in patients allergic to pollen. Ann Agr Env Med 2005; 12: 173-176.

12. Marseglia GL, Cirillo I, Caimmi S, Castellazzi AM, Ciprandi G. Clinical assessment of nasal decongestion test by VAS in adolescents. Pediatr Allergy Immunol 2009; 20: 187-191.

13. Ciprandi G, Klersy C, Ameli F, Cirillo I. Clinical assessment of a nasal decongestion test by visual analog scale in allergic rhinitis. Am J Rhinol 2008; 22: 502-505.

14. Eccles R, Eriksson M, Garreffa S, Chen SC. The nasal decongestant effect of xylometazoline in the common cold. Am J Rhinol 2008; 22: 491-496.

15. Ciprandi G, Cirillo I, Klersy C, Vizzaccaro A, Tosca MA, Marseglia GL. Association between response to decongestion testing and sensitizations and allergic infalamtion. Ann Allerg Asthma Im 2006; 96: 431-436. 
16. American Thoracic Society. Guidelines for metacholine and exercise challenge testing-1999: official statement of the American Thoracic Society. Am J Resp Crit Care 2000; 161: 309-329.

17. Sterk PJ, Fabbri LM, Quanjer P, Cockcroft DW, O`Byrne PM, Anderson SD, et al. Airway responsivness: standardized challenge testing with pharmacological, physical and sensiting stimuli in adults. Eur Resp J 1993; 6 (Suppl 16): 53-83.

18. Clement PAR, Gordts F. Consensus report on acoustic rhinometry and rhinomanometry. Rhinology 2005; 43: 169-179.

19. Kraneveld AD, Folkerts G, Van Oosterhout AJ, Nijkamp FP. Airway hyperresponsiveness: first eosinophils and then neuropeptides. Int $\mathbf{J}$ Immunopharmacol 1997; 19: 517-527.

20. Yamauchi K. Airway remodeling in asthma and its influence on clinical pathophysiology. Tohoku J Exp Med 2006; 209: 75-87.

21. Ciprandi G, Cirillo I, Vizzaccaro A, Monardo M, Tosca MA. Early bronchial airflow impairment in patients with persistent allergic rhinitis and bronchial hyperreactivity. Resp Med 2005; 99: 1606-1612.
22. Grossman J. One airway, one disease. Chest 1997; 111 (Suppl 2): $11-16$.

23. Demoly P, Bousquet PJ. Links between allergic rhinitis and asthma still reinforced. Allergy 2008; 63: 251-254.

24. Leynaert B, Neukirch C, Kony S, Guénégou A, Bousquet J, Aubier M, et al. Association between asthma and rhinitis according to atopic sensitization in a population-based study. J Allergy Clin Immunol 2004; 113: 86-93.

25. Linneberg A, Nielsen NH, Frolund L, Madsen F, Dirksen A, Jørgsen T. The link between allergic rhinitis and allergic asthma: A prospective population-based study. The Copenhagen Allergy Study. Allergy 2002; 57: 1048-1052.

26. Ciprandi G, Cirillo I. The lower pathology of rhinitis. J Allergy Clin Immunol 2006; 118: 1105-1109.

27. Drsata J, Vokurka J, Jakoubkova S. Rinomanometrie jako metoda funkcniho nosniho vysetreni. Otorinolaryngol Foniat 1999; 48: 21-28.

Received October 5, 2010. Accepted September 20, 2012. 